practical social problems. But more strictly considered, science seeks to establish valid generalizations concerning the properties of a range of natural phenomena, and its precision and explanatory value depend on the accuracy with which these properties are determined and the relations between them established. In this sense, social science must be concerned with the investigation of the nature and conditions of social relations, and should seek valid generalizations concerning variation in the social life of the human species. Interpretations of particular societies past or present, and predictions as to particular social developments in the future, depend for their penetration and ieliability on achievement in this more strictly scientific field. This dependence of advance in descriptive and practical studies on the development and application of theory is generally recognized in the field of economics, but has been less readily appreciated by students of social history, politics and ethnology.

Anthropology, traditionally concerned with the study of savage or pre-literate peoples, has developed in response to historical and practical, as well as scientific, interests. But interest in the organisation of these small-scale societies has been considerably stimulated by the hope of obtaining therefrom greater insight into problems of our own civilized societies through a better understanding of universal processes in the social life of man. The comparative study of the whole range of social forms is required for the formulating and testing of fundamental hypotheses concerning the nature of society. As in other scientific fields, advance is often easier with reference to less complicated material provided by small-scale 'primitive' societies. Moreover, the novelty and variety of institutions and social relations in such societies direct attention to problems which tend to be obscured by the particular conditions and conventional definitions current in our own society.

Anthropological studies in the field of culture have traditionally included both descriptive or ethnographic and analytical or sociological studies. It is important to recognize that as in other fields of knowledge, developments in each are interdependent. The scientific study of the social organisation of small-scale societies depends on the analysis of ethnographic data. Ethnography in turn has been rendered intrinsically more adequate and coherent by advances in sociological theory which have posed new questions and provoked new methods.

Thus earlier descriptions of societies organised in wide uni-lineal kin groups, of which only formal and ceremonial features were commonly emphasized, left obscure the processes whereby such groups were formed and maintained, and failed to reveal their role in maintaining social coherence and control among peoples where there is little specialization of activity and status. Analysis of rights and status in ritual, economic and political spheres has led to the discovery of a high degree of segmentation at a series of levels within these and other corporate bodies in other small-scale societies, and has revealed opposed tendencies to solidarity and fission within such groups as part of the adaptive character of social structure in relation to ecological conditions.

The study of corporate activity and leadership in small-scale societies shows that processes which in more complex societies are expressed in specialized religious, economic and political institutions are not absent among the former, but operate through less differentiated, multifunctional organisations. The categories of economies, religion, law and government are found to have wider reference and more variable inter-relations than is commonly recognized from the study of Western societies.

From the internal analysis of particular societies, and comparative studies, the range of conditions in which specialized institutions emerge are being more closely determined. Spencer's hypothesis of social evolution greatly stimulated the development of social anthropology in the nineteenth century. The comparative study of institutions in relation to the total social structure on one hand, and the ecological foundations of social life on the other, promises to yield a theory of social development more valid than the unverifiable speculations concerning the social conditions of early man into which interest was temporarily diverted in the nineteenth century.

\section{WIDER APPLICATIONS OF TEACHING OF PHYSIOLOGY}

$T$ HE main feature of Prof. Winifred Cullis's address to Section I (Physiology) is a plea for the training of more physiologists and a wider use of their services. Physiology, if it is to take its proper place in education, has a dual function to perform. Its importance in the teaching of medical students is well recognized; but there is too little appreciation of its other aspect as a science which, apart from its medical bearing, is important for the general health of the community. A plea for a wider recognition of this aspect was chosen for the address, not only because Prof. Cullis's war-time experience broke her contact with the more academic side of physiology, but also because in her opinion it is one insufficiently recognized and one in which she is able to draw upon personal experience.

The community owes much to physiology and is interested in hearing of this debt. The newer knowledge of nutrition, with which will always be associ ated the name of Sir Frederick Gowland Hopkins, has shown its use in dealing with the restrictions imposed by war-time conditions. The story of insulin, itself of great interest, has a special value in these days of popular writings, in giving some idea of the time that may elapse between the making of a discovery and its safe and general application. The decision of the men of Smithfield not to increase the price of pancreatic material, after hearing what this material could mean in giving to diabetic patients the chance of an active life, is a dramatic instance of the value of knowledge. Possibly, too, a better knowledge of physiological principles might enable the public to evaluate more correctly some of the fantastic claims made in advertisements of certain preparations.

Well-qualified teachers of physiology would be of use in many directions. They are much needed in the general training colleges as well as in those devoted to the training of teachers of domestic science and of physical training. They would be of great value in schools in the upper forms, where they could build upon the foundations often so well laid in the junior forms by good biology teaching. In these institutions and in industrial establishments they could be of use in collecting the normal physiological data now recognized as necessary in the departments 
of social medicine. Social science workers would be helped by such instruction, and in extra-mural university classes and in adult education such teachers could play an important part.

To provide these teachers it will be necessary for the universities to increase the number of students taking honours courses in physiology, but who are not going on to medicine. It will also be necessary for the various educational institutions to realize the value of having on their staffs teachers so trained.

In schools, broadcasting and films can be useful aids, though they in no way lessen the responsibility of the class-room teacher, from whom the main inspiration must always come. In preparing such aids it is necessary to have co-operation between three sets of experts, the class-room teacher and the experts in the subject and in the medium to be used. It is necessary, too, for teachers to have training in the of such use aids.

It is Prof. Cullis's firm conviction that this wider teaching of physiology would result in a better understanding of various problems intimately associated with healthy living, so leading to a higher and better standard of health for the individual.

\section{MAN'S ADAPTABILITY}

$\mathrm{T}$ $H E$ question of the adaptability of man was the theme of Dr. S. J. F. Philpott's address before Section $J$ (Psychology). Many of the problems psychologists have handled during the War and that will face them during the peace have had to do with man's adaptability. Can a bank clerk be changed, almost overnight, into a tank gunner ? Can he be changed back by a stroke of the pen?

If the doctrine of round pegs in round holes were strictly true such transformations would be difficult, if not impossible. In practice, they can take place with surprising ease, especially if the will to act is present. There are limits. Broadly speaking, men are only adaptable within the limits of their all-round ability; but granted the will and the ability, man can play many parts.

In asking just how an individual is equipped and just how he can adapt himself, we must realize that he works as a whole. When in the workshop planing or sawing a piece of wood, it is my body as a whole that I use, throwing it now into the attitude appropriate to the use of a plane, now into the attitude appropriate to the use of a hand saw. I do not use a planing organ or a sawing organ.

In similar fashion, I am now in the mental attitude appropriate to making an abstract. In a moment I may be in the frame of mind appropriate to making some calculations, or writing a letter, and so on. It is my mind as a whole that I use in each of these operations. I do not use an abstracting organ or a calculating organ.

The problem of education into a given culture is that of giving the individual an enormous number of such attitudes, skills or techniques, ranging from the simplest of everyday actions like opening doors up to the highest expression of the arts and sciences. We only begin to realize the significance of the complex of skills thus built up when we learn about 'wolf children' realizing how much they have lost. Yet no matter how complex the result of all this training, it still remains that all activities can be traced to the functioning of the one general-purposes body-mind instrument.

The problem of drill arises whether in peace or war. It is that of making these various techniques automatic. One cannot enjoy riding a bicycle until all movements of hands and feet and body take place well below the conscious level. No.man can be master of his craft until he has made himself a slave to the minor habits involved, the fingering of his instrument or the handling of his tools.

Before advising training, we often to-day apply tests of potentiality. The naive view is that we ought to be able to devise tests to distinguish between those born to be tank gunners and those born to be tank drivers. In fact, a one-time carpenter can often succeed at either of the other two occupations. Granted that at the moment he knows nothing about either of them, will tests for potential drivers or potential gunners pick him out? If so, will it not be a case of a test for drivers picking out a potential gunner? Or so far as that goes, will it not have picked out an actual carpenter ? Put briefly, although it is easy to devise tests of all-round ability (trainability or adaptability) it is quite another matter to discover tests that shall assess potentiality in respect of some one occupation and it alone. There is wide overlap. The bearing of this on problems of peace, such as that of advising children into the best form of education, is obvious.

\section{THE HISTORY OF PLANT FORM}

$\mathrm{A}$ LTHOUGH in recent years botanists have been mainly interested in the study of growing plants, many of their generalizations are based on a belief that evolution has taken place in the plant world. But since very little historical evidence of the evolu. tion of the flowering plants has been forthcoming, this belief has become a dogma, maintained in spite of the absence of proof. This unsatisfactory position, said Dr. H. Hamshaw Thomas, in his presidential address to Section K (Botany), warrants a survey of our present knowledge of the fossil record.

Past failure to find any clues to the early history of the flowering plants may be due to a deductive examination of the evidence. The logical basis of evolutionary study is different from that of pure or typological morphology, but it has been assumed that the Urform of the pure morphologist represents the primitive type of flowering plant. Consequently we may have been searching for structures which have never existed. The actual record of changes in plant form through the ages suggests the evolution of the angiosperms through types very different from those imagined.

The geological record becomes clearer if we com. pare the plant forms from successive terrestrial periods, dividing the geological time-scale in a manner complementary to the normal classification of strata, the groups of which represent periods of marine sedimentation. Owing to the rare conditions under which plants are preserved as fossils, we can never hope to trace real phylogenies, but we can obtain evidence of the ways in which structures have changed in the past 400 million years.

The remains of the Upper Silurian-Lower Devonian land plants show forms widely different from the plants of to-day. Types with smooth forking axes predominated; they had little differentiation into 